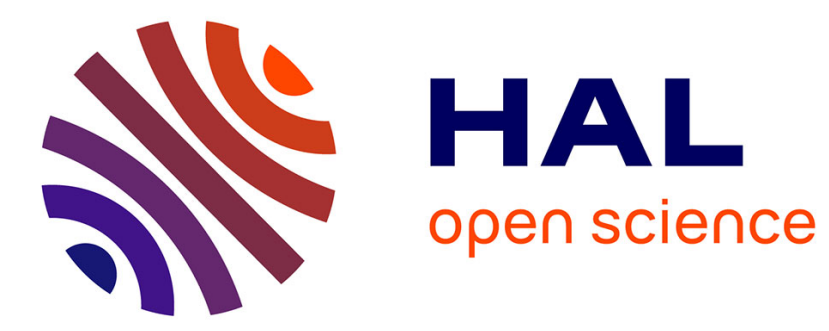

\title{
Space grease lubrication modeling: A discrete element approach
}

\author{
Magali Busquet, Mathieu Renouf, Yves Berthier, Jacques Sicre
}

\section{To cite this version:}

Magali Busquet, Mathieu Renouf, Yves Berthier, Jacques Sicre. Space grease lubrication modeling: A discrete element approach. Tribology International, 2017, 111, pp.159 - 166. 10.1016/j.triboint.2017.03.002 . hal-01555529

\section{HAL Id: hal-01555529 \\ https://hal.science/hal-01555529}

Submitted on 4 Jul 2017

HAL is a multi-disciplinary open access archive for the deposit and dissemination of scientific research documents, whether they are published or not. The documents may come from teaching and research institutions in France or abroad, or from public or private research centers.
L'archive ouverte pluridisciplinaire HAL, est destinée au dépôt et à la diffusion de documents scientifiques de niveau recherche, publiés ou non, émanant des établissements d'enseignement et de recherche français ou étrangers, des laboratoires publics ou privés. 


\title{
Space grease lubrication modeling: A discrete element approach
}

\author{
Magali Busquet ${ }^{\mathrm{a}, \mathrm{e}, *}$, Mathieu Renouf ${ }^{\mathrm{b}, \mathrm{c}}$, Yves Berthier ${ }^{\mathrm{a}, \mathrm{c}}$, Jacques Sicre ${ }^{\mathrm{d}}$ \\ a Université de Lyon, CNRS INSA-Lyon, LaMCoS UMR5259, F-69621, Villeurbanne, France \\ b Laboratoire de Mécanique et Génie Civil (LMGC), Université de Montpellier, CNRS, Montpellier, France \\ ${ }^{\mathrm{c}}$ International Tribology Group (InTriG), Villeurbanne, France \\ d CNES (Centre National des Etudes Spatiales), 18, Avenue Edouard Belin, bpi 1715, 31 401, Toulouse, France \\ e InS-Innovation - Nanomaterials \& Strategy (Filiale du groupe Crescient), 450 Rue Ampère, 69730 Genay, France
}

\begin{abstract}
The tribological behavior of space grease is investigated with the Discrete Element Method. In the first step, the grease is described as a collection of particles of two kinds (oil and PTFE) in interaction. The development of the Grease Discrete Element Model (GDEM) used here, is based on rheometer-like characterizations. In the second step, the GDEM is subjected to tribometer-like conditions to investigate grease flow mechanisms and the role of the thickener (PTFE) in lubrication. The tribological behavior of grease seems to be controlled by the coupled influence of both granulometric (thickener particle sizes) and physico-chemical (interaction law) parameters. These results provide the starting point for identifying the parameters on which to act to reformulate greases.
\end{abstract}

Keywords:

Space greases

Discrete element

Fluid/particle

Lubrication

\section{Introduction}

In the case of space applications, grease is commonly used as a fluid lubricant to minimize oil migration outside the contact and contamination mechanisms. Moreover, there are specific requirements due to the absence of gravity, very low ambient pressures and large temperature variations $[1,2]$. As the performances of lubricants clearly influence the mechanical reliability of space assemblies [3,4], the increasing complexity of spacecraft and satellites is directly linked to tribological problems. Thus, as has been understood for many years [5], it is vital to understand and control not only the rheological properties of space greases but also their tribological behavior.

Two approaches can be followed to design such dedicated greases. The first is to improve existing lubricants through iterative assessments on different laboratory tribometers that reproduce space tribological conditions and accelerate full life scale testing. The second approach is to develop significant grease tribological models that reproduce grease flows using the relevant parameters on which to act to control behavior and reformulate the grease.

Grease is composed of lubricating oil and a thickener. In addition to soaps [6], lubricating "additives" such as PTFE [7-12] are used as thickeners. Some experimental works [11,12] compared the relative lifetime, friction factor and degradation rates of PTFE greases, while others [7-10] investigated the role of PTFE during lubrication. In particular, under some circumstances, PTFE greases no longer behave as oils as the PTFE particles have been observed spread on friction surfaces, or the largest particles are accumulated at the contact entrance and prevent smaller particles and even oil from fulfilling their role of lubrication [9]. The direct tribological role of thickeners was also identified for non-space grease lubricated bearings, especially under low speed conditions [13-19]. This is of interest as most space mechanisms $[1,2]$ move at low speeds. The solid-like lubrication films observed were much thicker that the predicted oil EHL (Elasto-HydroLubrication) film thickness and had higher thickener content. In parallel to experimental investigations, an increasing number of complex rheological models have been proposed to describe the nonlinear behavior of lubricating greases, ranging from empirical steadystate flow descriptions involving yield stress $[20,21]$ to transient flow responses including viscoelastic and thixotropic effects [22-25], and EHL numerical analysis [26-28]. While these global models can describe grease behavior when thickeners play only an indirect role, experimental evidence has shown that classical continuous mechanics tools cannot describe the complexity of grease behavior, especially the direct tribological role of thickeners [7-10,13], due for the most part to the hypothesis of continuous mechanics used in the model which is not always satisfied in a real contact.

Thus alternative models must be used to overcome this difficulty. Nowadays, coupling continuous and discontinuous aspects is still a numerical challenge especially under contact conditions. Although several approaches allow simulating fluid/particle mixtures [29-31],

\footnotetext{
* Correspondence to: INSA-Lyon, Laboratoire de Mécanique des Contacts et des Structures, 18-20 rue des Sciences, F69621 Villeurbanne Cedex, France.

E-mail addresses: magali.busquet@insa-lyon.fr (M. Busquet), Mathieu.Renouf@univ-montp2.fr (M. Renouf), yves.berthier@insa-lyon.fr (Y. Berthier), jacques.sicre@cnes.fr (J. Sicre).
} 
contact conditions are never taken into account, mainly due to the continuous description of the fluid.

The objective of the present work is to investigate the use of discontinuous mechanics to model tribological grease flows by using a Discrete Element approach. Such approaches are commonly used in tribology for dry lubrication problems $[32,33]$ but can also be used to model full fluid flows [34] and continuous solid structures [35]. In the same vein, grease is therefore considered as a collection of two kinds of particle: one to represent oil and the other PTFE. In this initial attempt, the aim is not to provide a predictive tool but to propose a qualitative one to improve understanding of the complex discontinuous behavior of the grease under contact conditions. Section 2 presents the numerical framework used to represent the Grease Discrete Element Model (GDEM) and the associated parameter identification procedure based on rheometer-like simulations. Section 3 is dedicated to the investigation of GDEM behavior under tribological conditions, while the final section proposes conclusions and perspectives.

\section{Development of the Grease Discrete Element Model (GDEM)}

\subsection{Numerical framework}

Discrete Element Methods (DEM) are usually used to model the evolution of a large number of particles in interaction [36-38]. In the present case, they are used in a meshless approach and the particles are used to discretize the grease domain, as has already been done for solid continuous domains [35]. The main advantages of using DEM to model grease is to take into account both accurate contact conditions and grease separation (i.e. PTFE distribution changes within grease). The main difficulty resides in identifying the interaction laws between elements which should lead to obtaining an equivalent continuous behavior in agreement with experimental data [39].

Thus the grease domain is represented as a collection of contacting bi-dimensional rigid discs. Two kinds of particle are necessary. The first represents the viscous fluid (oil particles) while the other represents the thickener (PTFE particles) (cf. Fig. 1(a) and (b)). This discretization involves five interactions: "volume" interactions (oil/oil, PTFE/PTFE and oil/PTFE) and "surface" interactions (oil/boundary and PTFE/ boundary) (cf. Fig. 2). For example, the oil/PTFE interaction should account for the chemical affinities between PTFE particles and oil while the oil/oil interaction should ensure that the whole set of oil particles matches the oil behavior at the macroscopic level (in homogenization).

In the first approach, the different interactions rely on a cohesive unilateral law already used to represent cohesive media [33] and based on two parameters: a cohesive attractive force denoted $\gamma$ and a distance interaction denoted dw (cf. Fig. 3(b)). This contact law can be formulated as:

$g \geq O\left(R_{N}+\gamma\right) \geq 0 g .\left(R_{N}+\gamma\right)=0$

where $R N$ represents the normal part of the contact force and $g$ the distance between two particles. Thus when two particles are separated of a distance greater than dw, no interaction force acts on them. When the separation distance is smaller than $d w$, the attraction force is activated, getting particles closer (cf. Fig. 3). Such a law confers to a given volume a viscous behavior. Moreover the unilateral relation between particles in contact allows to respect the incompressibility of the whole medium. At a given time step, for each particles, all interaction are identified (attraction and contact forces), allowing the motion of the set of particles.

\subsection{Identification procedure}

The development of the GDEM relies on two phases based on rheometer-like characterizations: first, the single oil and then the oil/ PTFE mixture. Bi-dimensional shear cells with a dimension equal to $1.10^{\mathrm{E}-6} \mathrm{~m}$ in both directions are used to determine the different parameters (Fig. 1(a) and (b)). Periodic conditions are used in the shear direction while rough surfaces are used as boundary conditions in the perpendicular shear direction to contain the domain and apply a shear velocity (lower boundary) equal to $1000 / \mathrm{s}$. The distance between the two boundaries is maintained constant. For the present study, the comparisons are based on previous works $[40,41]$ for which space oil (both mineral oils, such as Fomblin Z25 and synthetic oils, such as Penzanne 2001 A were used) and grease viscosities are measured (for the grease, a cone-plate rotational rheometer was used, cf. diagrams in Fig. 4(a)). For the grease considered, the viscosity of the oil is about 0.26 Pa.s, 1.4 Pa.s for the grease, for a shear rate of $1000 / \mathrm{s}$ at $20^{\circ} \mathrm{C}$. For the simulation, the dynamic viscosity, denoted $\eta$, is calculated as the ratio of the shear stress $(\mathrm{Rx} / \mathrm{Lx})$ to the shear velocity gradient (with $\Delta(\mathrm{Vx}) / \Delta(\mathrm{Ly})=\mathrm{Vx} /$ Ly with a constant gradient, cf. Fig. 1 (Rx: shear reaction force in the $\mathrm{X}$-direction at the lower boundary).

\subsection{Oil characterization}

To determine the $\left(\gamma_{\mathrm{o} / \mathrm{o}}, \mathrm{dw}_{\mathrm{o} / \mathrm{o}}\right)$ pair, we first used a model composed of only oil particles (cf. Fig. 1(a)). It is composed of 1100 elements. The average oil particle size is equal to $3.10^{\mathrm{E}-8} \mathrm{~m}$. It was considered that several oil molecules are necessary to model the oil flowing in film thickness, estimated to vary from a few to $400 \mathrm{~nm}$ in previous experimental work from EHL theory [9]. In this configuration, the oil/boundary interaction parameters (denoted $\gamma_{\mathrm{ob}}$ and $\mathrm{dw}_{\mathrm{ob}}$ ) are equal to those of the oil/oil interaction (denoted $\gamma_{\mathrm{oo}}, \mathrm{dw}_{\mathrm{oo}}$ ). Several simulations were performed for different cohesion forces $\left(\gamma_{\mathrm{oo}}\right)$ while the cohesion distance $\mathrm{dw}_{\text {oo }}$ was kept constant, at $10 \%$ of the oil particle radius. The results are summarized in Fig. 5 . It can be seen that the viscosity increases as the cohesion increases, then the final set of parameters $\left(\gamma_{o o}, d_{w_{o o}}\right)$ is determined as the cross section between the resulting curve and the experimental data.

\subsection{Grease characterization}

The introduction of PTFE leads to the use of two other sets of parameters, related to PTFE/PTFE interactions, denoted $\left(\gamma_{\mathrm{PP}}, \mathrm{dw} \mathrm{wP}_{\mathrm{PP}}\right.$

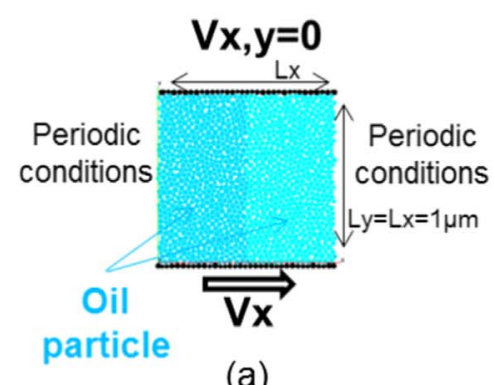

(a)

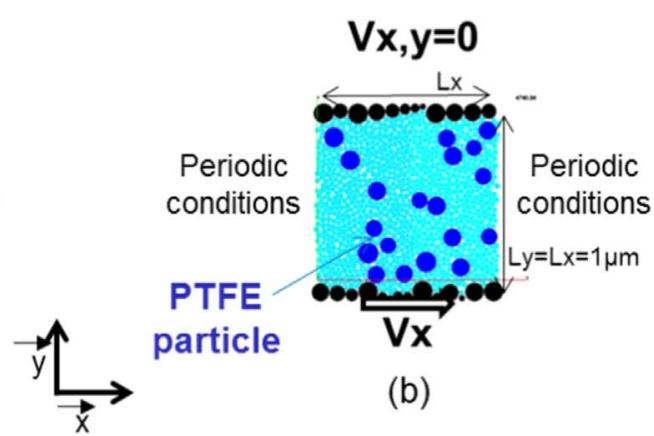

Fig. 1. The two DEM developed, (a) the Oil Discrete Element Model, (b) the Grease Discrete Element Model. 


\begin{tabular}{|c|c|c|c|c|c|}
\hline & \multicolumn{3}{|c|}{ Volume } & \multicolumn{2}{c|}{ Surface } \\
\hline Interaction & oil / oil & PTFE / PTFE & oil / PTFE & oil / boundary & PTFE / boundary \\
\hline Schematics & & & & & \\
\hline $\begin{array}{c}\text { Parameters involved } \\
\text { ( } \begin{array}{c}\text { : force, dw: distance } \\
\text { between 2 particles) }\end{array}\end{array}$ & $\gamma_{\mathrm{oo}}, \mathrm{dw}_{\mathrm{OO}}$ & $\gamma_{\mathrm{PP}}, \mathrm{dw}_{\mathrm{PP}}$ & $\gamma_{\mathrm{OP}}, \mathrm{dw}_{\mathrm{OP}}$ & $\gamma_{\mathrm{ob}}, \mathrm{dw}_{\mathrm{ob}}$ & $\gamma_{\mathrm{Pb}}, \mathrm{dw}_{\mathrm{Pb}}$ \\
\hline
\end{tabular}

Fig. 2. Five interactions involved in the bi-phasic discrete element model.

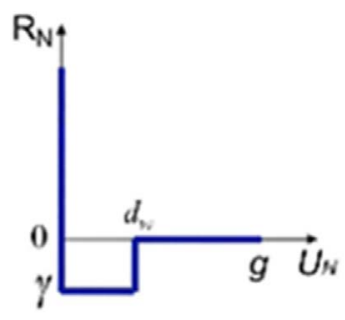

(a)

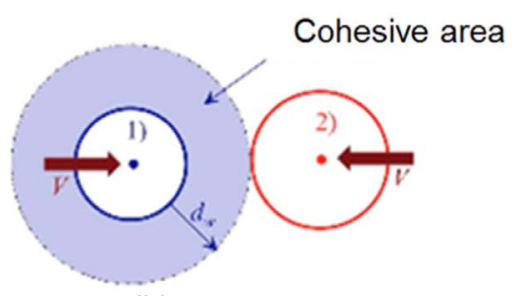

(b)

Fig. 3. Cohesive unilateral contact law. (a) The normal component of the interaction force $R_{N}$ versus g, the distance between particles. For $0<\mathrm{g}<\mathrm{dw}$, this corresponds to the maximal cohesion force $\gamma \square$ (b) The cohesive attraction area defined by the distance $\mathrm{dw}$, between two particles 1) and 2).

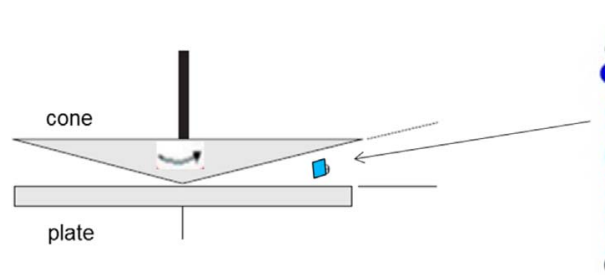

(a)

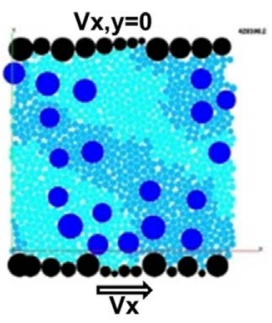

(b)

Fig. 4. (a) Cone-plate rotational rheometer (cone diameter: $4.10^{\mathrm{E}-2} \mathrm{~m}$, angle: $1^{\circ}$ ), (b) the Grease discrete element model.

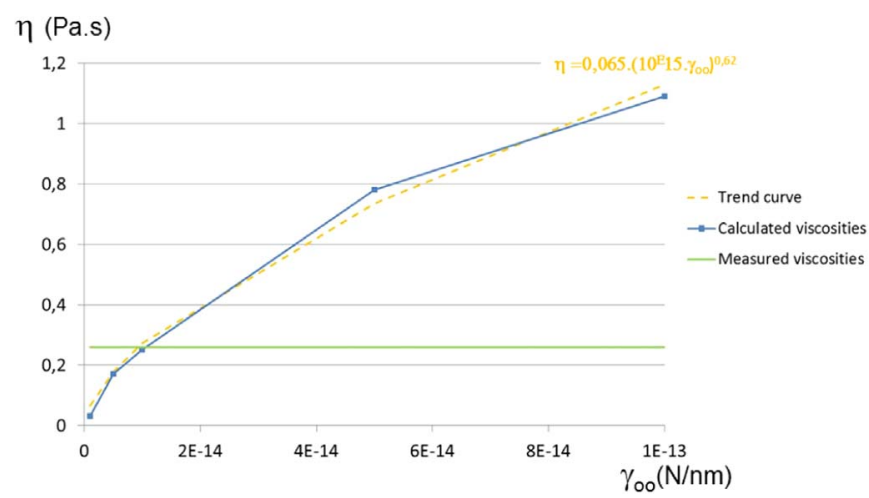

Fig. 5. Evolution of the viscosities $\eta$ (Pa.s) s) versus the oil/oil interaction parameter $\gamma_{\text {oo }}$ $\left(10^{\mathrm{E} 9} \mathrm{~N} / \mathrm{m}\right)$. The real oil viscosity measured is also plotted for comparison.

and to the oil/PTFE interactions $\left(\gamma_{\mathrm{oP}}, \mathrm{dw}_{\mathrm{oP}}\right)$. The simulation sample presents the same characteristics as the previous analysis, completed by PTFE particles with a mean diameter $\phi_{(\mathrm{PTFE})}$ equal to $1.10^{\mathrm{E}-7} \mathrm{~m}$, a particle size distribution of $+/-20 \%$ (according to experimental observations $[12,41]$ ), and with a volume fraction of 0.25 . The GDEM model is composed of 1100 elements including 20 PTFE

particles. To investigate model size effects, a larger model was developed (5500 elements) which tended to confirm the general trends. Fig. 6 presents the evolution of viscosity as a function of the ratio $\gamma_{\mathrm{oP}} /$ $\gamma_{\mathrm{PP}}$ for two attraction distances between the oil and the PTFE particles: $\left(\mathrm{dw}_{\mathrm{O} / \mathrm{P}} / \phi_{(\mathrm{PTFE})}=0.01\right)$ and $\left(\mathrm{dw}_{\mathrm{O} / \mathrm{P}} / \phi_{(\mathrm{PTFE})}=0.5\right)$ (with $\mathrm{dw}_{\mathrm{P} / \mathrm{P}} / \phi_{(\mathrm{PTFE})}$ $=3$ ). The experimental viscosity value is represented by the horizontal green line. Fig. 7 shows the distribution of PTFE within the GDEM after the lower surface has reached distance Lx for two sets of parameters leading to (a) PTFE cluster formation and (b) no PTFE cluster formation. From these results, it can be observed that the GDEM viscosity increases as the following increase:

- the ratio $\left(\gamma_{\mathrm{o} / \mathrm{P}} / \gamma_{\mathrm{P} / \mathrm{P}}\right)$,

- the distance $\left(\mathrm{dw}_{\mathrm{o} / \mathrm{P}}\right)$ (the red and blue lines for $\left(\mathrm{dw}_{\mathrm{o} / \mathrm{P}} / \phi_{(\mathrm{PTFE})}\right.$ $=0.01)$ and $\left(\mathrm{dw}_{\mathrm{O} / \mathrm{P}} / \phi_{(\mathrm{PTFE})}=0.5\right)$, respectively $)$.

The results are shown to be strongly dependent on the relative influence between the interactions (oil/PTFE) and (PTFE/PTFE). A more pertinent parameter, called $\left(\mathrm{R}_{(\mathrm{o} / \mathrm{P}) /(\mathrm{P} / \mathrm{P})}\right)$ defined as the ratio of the relative energies of the two interactions, could therefore characterize their relative influence more completely (with $\mathrm{R}_{(\mathrm{o} / \mathrm{P}) /(\mathrm{P} / \mathrm{P})}=\left(\gamma_{\mathrm{O}} /\right.$ $\left.\left.\mathrm{P}^{*} \mathrm{dw}_{\mathrm{O} / \mathrm{P}}\right) /\left(\gamma_{\mathrm{P} / \mathrm{P}}{ }^{*} \mathrm{dw}_{\mathrm{P} / \mathrm{P}}\right)\right)$. The results also show that several combinations of parameters $\left(\gamma_{\mathrm{o} / \mathrm{P}}, \mathrm{dw}_{\mathrm{o} / \mathrm{P}}\right)$ and $\left(\gamma_{\mathrm{P} / \mathrm{P}}, \mathrm{dw}_{\mathrm{P} / \mathrm{P}}\right)$ could result in the same viscosity. The three parameter combinations used to compute a viscosity close to that measured can be associated with the conservation of the initial PTFE distribution within the GDEM. For a given distance $\left(\mathrm{dw}_{\mathrm{O} / \mathrm{P}} / \phi_{(\mathrm{PTFE})}\right)$ and force $\left(\gamma_{\mathrm{P} / \mathrm{P}}\right)$, the decrease of viscosity could be associated with the formation of PTFE agglomerates. The presence of agglomerates can change the location of velocity accommodation within the oil (or at the formed boundary between the oil and the agglomerates) which can explain why the resulting calculated viscosity is too low, as the viscosity of the grease was shown to be fifteen times higher than that of the oil. The viscosity parameter is thus not sufficient alone to characterize the "volume" interaction law parameters associated with a given grease. However, the order of magnitude of the sets of parameters determined can be used as starting points for the tribological model in the next section.

\section{Tribological analysis}

\subsection{Introduction}

Once the volume properties of the GDEM were identified, the model was subjected to tribometer-like conditions close to those obtained from previous experiments [7-9], i.e. confinement between two bodies (cf. Fig. 8(a1) and (a2)). Thus, in such a situation, the effect of possible PTFE agglomerations was analyzed as was the influence of the interaction between the grease and the surface, which can be of the first order for vacuum applications (no reacting gas, no protective boundary, etc). 

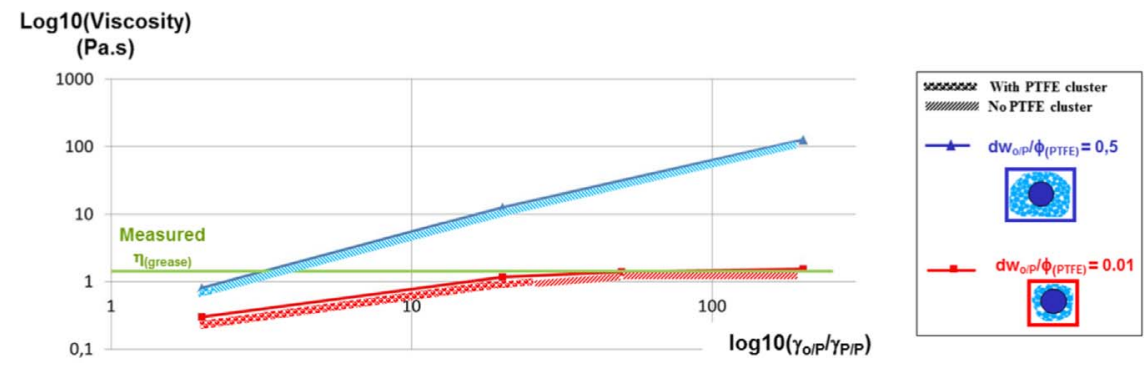

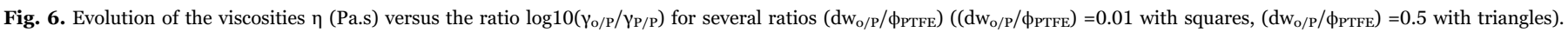

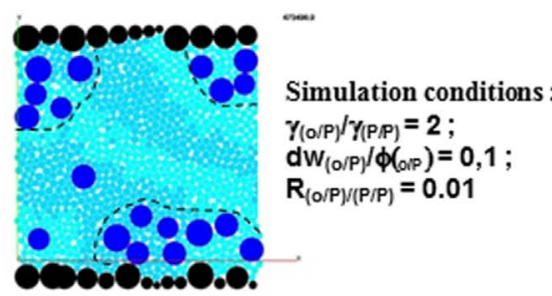

(a)

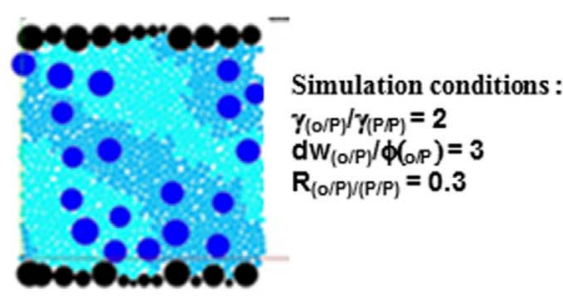

(b)

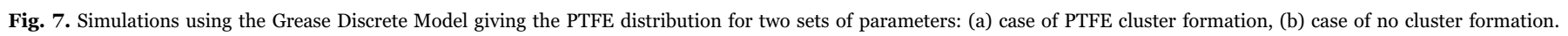

\subsection{Model description}

To reproduce the contact conditions, the GDEM was sheared in a double convergent model of $1,5.10^{\mathrm{E}-5} \mathrm{~m}$ length (cf. Fig. 8(b)). The maximum height was equal to $5.10^{\mathrm{E}-6} \mathrm{~m}$ while the minimum height, corresponding to the convergent thickness, was equal to $5.10^{\mathrm{E}-7} \mathrm{~m}$. The boundaries had a roughness equal to $4.10^{\mathrm{E}-8} \mathrm{~m}$. A constant distance was maintained between them to ensure no volume variation. Lateral periodic conditions were imposed to model the large lateral dimensions of the real contact and maintain a grease reserve. An alternative velocity in the X-direction of $4.10^{\mathrm{E}-4} \mathrm{~m} / \mathrm{s}$ was given to the lower boundaries. In Section 2, the oil model particle size was about $3.10^{\mathrm{E}-8} \mathrm{~m}$ (modeling choice) while the PTFE particle size was about $1.10^{\mathrm{E}-7} \mathrm{~m}$ (physical data). The use of such granulometry here would lead to handling at least $10^{\mathrm{E} 6}$ element interactions (already at the beginning of shearing), which is difficult to process in terms of computational time. To find a compromise between the physical and numerical constraints, it was decided to increase the particle sizes of the oil and PTFE models, with $\phi_{\text {oil }}=1.10^{\mathrm{E}-7} \mathrm{~m}$ and $\phi_{(\mathrm{PTFE})}=2.10^{\mathrm{E}-7} \mathrm{~m}$ $\left(\phi_{\text {(PTFE) }} / \mathrm{h}=0.4\right)$ and keep the same volume. The resulting reference model was composed of 4055 elements. It was considered that the ratio of the cohesive force or cohesive attraction area distance over the particle diameters was constant, i.e. $\left(\gamma / \phi_{(\mathrm{PTFE})}=\right.$ constant $)$ and $(\mathrm{dw} /$ $\phi_{(\mathrm{PTFE})}=$ constant) . To investigate the role of PTFE particle size under tribological conditions, a second distribution of PTFE particle size, larger than the previous one $\left(\phi_{(\mathrm{PTFE})}=4 \cdot 10^{\mathrm{E}-7} \mathrm{~m}\right)$, was used. The proportion of PTFE in the GDEM and the size of the cell remained unchanged. Fig. 9(a) and (b)) both present the two models, $\mathrm{m} 1$ and $\mathrm{m} 2$, developed. Regarding the "volume" interaction parameters, two sets (called $\mathrm{C} 1$ and $\mathrm{C} 2$ ) were defined that either allowed PTFE particle agglomeration or not (cf. Table 1). Regarding the "surface" interaction parameters, the interactions (oil/surface) and (PTFE/surface) modeled

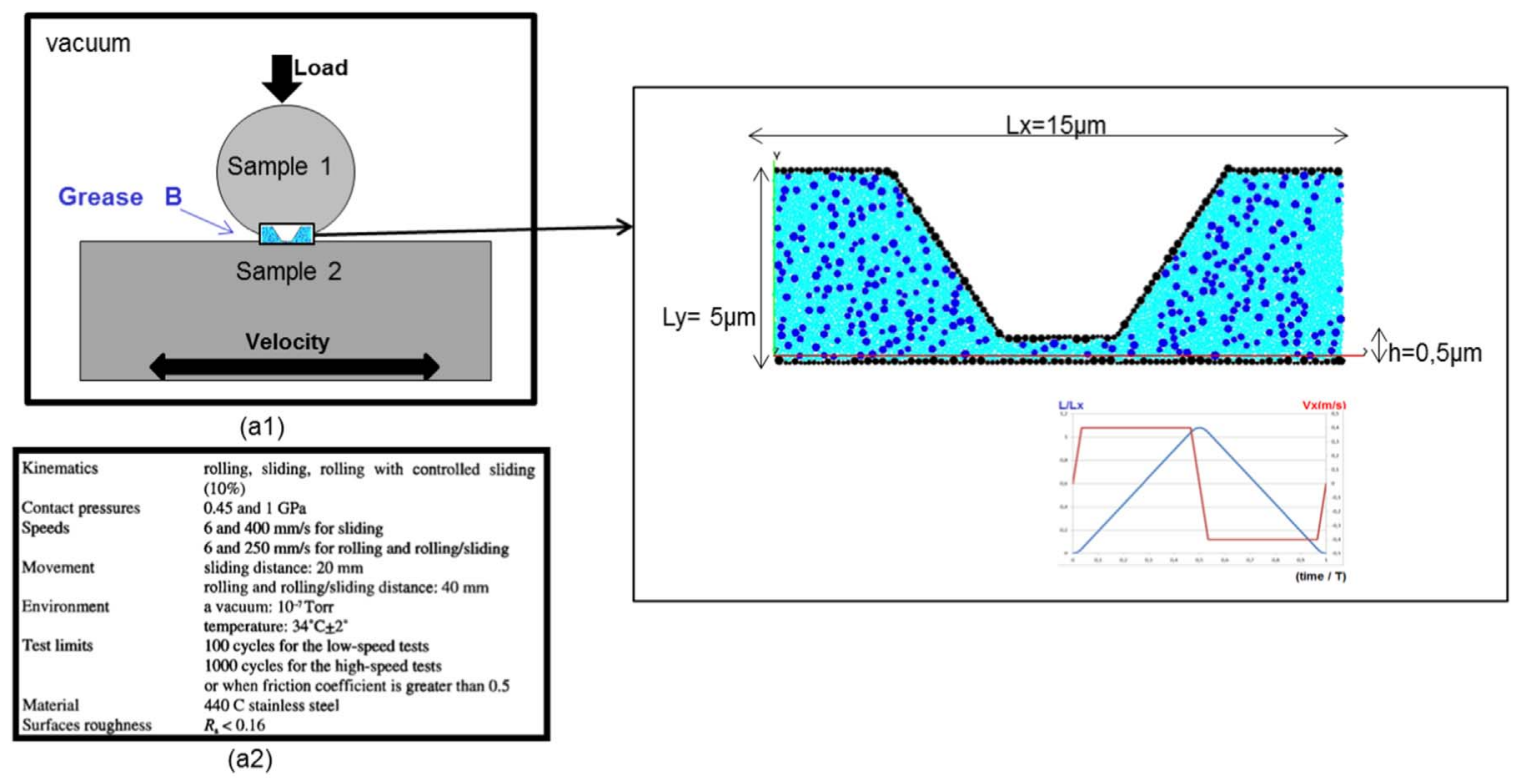

(a)

(b)

Fig. 8. (a) Experimental works on space grease [8-10], (a1) experimental set up, (a2) test conditions, (b) Tribological reference model. 


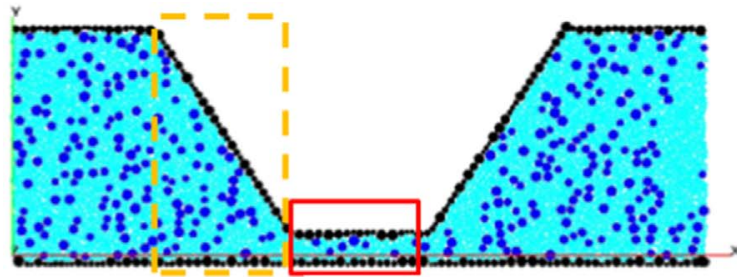

(a)

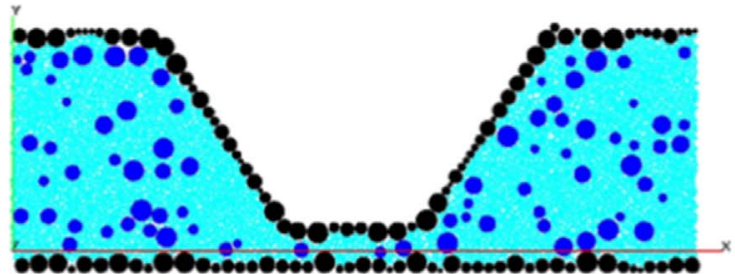

(b)

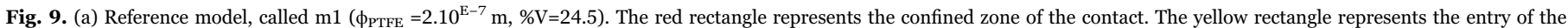

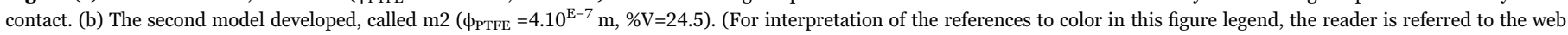
version of this article.)

the adhesion between the oil and the PTFE particles and the real surfaces. A second parameter $\left(\mathrm{R}_{(\mathrm{P} / \mathrm{b}) /(\mathrm{o} / \mathrm{o})}\right)$ was defined as the ratio of the energies between the interactions (PTFE/boundary) and (oil/oil), (with the interaction (oil/boundary) parameters taken as equal to those of the (oil/oil) interaction). The results with several values of $\left(\mathrm{R}_{(\mathrm{P} / \mathrm{b}) /(\mathrm{o} /}\right.$ o) are presented in the present paper.

To quantify the results and investigate their evolution versus time, some key parameters were defined as follows:

1. $\mathrm{N}_{\mathrm{p}}=\% \mathrm{~N} \_\mathrm{PTFE}$, the relative number of PTFE particles within the confined zone of the contact, with \%N_PTFE=N_PTFE/ N_PTFE_total (cf. the full red rectangle in Fig. $9(\mathrm{~b} 1)$ ),

2. \%N_PTFE_blocking, the relative number of PTFE particles agglomerated at the contact entry, with \%N_PTFE_blocking= N_PTFE_blocking/ N_PTFE_total (cf. the dotted yellow rectangle in Fig. 9(a)),

3. $(\mu)$, the friction factor is defined as the ratio of the tangential force $T$ measured on the lower surface and of the normal force $\mathrm{N}$ measured on the upper surface

The calculation times were long 5-15 days of calculation to perform a return cycle for the reference model on a parallelized 4-node system with 2 GB RAM on an Intel(R) Xeon(R) CPU E5-2660 v2@2.20 GHz computer).

\subsection{Results and discussion}

\subsubsection{General trends}

From each simulation considered (Table 1), an image was extracted after one return cycle (cf. Fig. 10) for the two extreme "surface" parameter values to investigate the evolution of particle distribution. Some clear differences in PTFE particle distribution could be highlighted according to the interaction parameters (considered combinations $\mathrm{Ci}-\mathrm{j}$ ) and the granulometry (model $\mathrm{m} 1$ or $\mathrm{m} 2$ ). As expected, for the C1-1 combination (cf. Fig. 10(a)), the initial distribution of the PTFE particles in the model was kept constant during one cycle. The PTFE particles "follow" the oil flow entrained by the driving boundary surface within the confined zone of the convergent, where only a few particles can be observed. For the C2-1 combination (cf. Fig. 10(c)), the initial PTFE particle distribution is modified during the first stroke as agglomerates form. Their size and number depend on their granulometry. The formation of PTFE agglomerates (or not) could be observed in Section 2.4 in the rheometer-like simulations, depending on the relative influence between the interactions (oil/PTFE) and (PTFE/ PTFE). Under tribological conditions, PTFE agglomeration in clusters can also occur, activated by the relative motions of the surfaces (conditions of pressure and shearing) as well as confinement. The velocity accommodation generates several PTFE particle streams leading to the activation of physico-chemical interactions. Under these circumstances, no PTFE particles were entrained within the contact for the stroke studied (to be validated for a longer stroke). The same "volume" combination was tested for the strongest PTFE particlesurface adhesion conditions (cf. Fig. 10(b) and (d)) tested. It can be observed that the moving boundary surface attracts and entrains the PTFE particles within the confined zone, forming a "solid-like" layer with a high PTFE particle concentration (cf. Fig. 10). Under such conditions, the number of PTFE particles within the confined zone of the contact and the number of particles "stuck" on the moving surface seems to increase whatever the combination and granulometry. In particular, for the second PTFE particle size, the particles can be seen to accumulate at the contact entrance (cf. Fig. 9(d2)). These trends are confirmed by Fig. 11(a), where the evolution of $\left(\mathrm{N}_{\mathrm{p}}\right)$ is plotted for the two "volume" properties C1 (dotted line) and C2 (full line) and to the two extreme "surface" adhesion conditions considered (C1-1 in red and C1-6 in blue, cf. Table 1). This confirms that $\left(\mathrm{N}_{\mathrm{p}}\right)$ increases with the increase of the parameter $\left(\mathrm{R}_{(\mathrm{o} / \mathrm{P}) /(\mathrm{P} / \mathrm{P})}\right)$. While a clear distinction can be observed between the two combinations $\mathrm{C} 1$ and $\mathrm{C} 2$ for the lowest $\left(\mathrm{R}_{(\mathrm{o} /}\right.$ $\mathrm{P}) /(\mathrm{P} / \mathrm{P})$ ), the results tend to converge for the highest $\left(\mathrm{R}_{(\mathrm{O} / \mathrm{P}) /(\mathrm{P} / \mathrm{P})}\right)$, to the same value of $\left(\mathrm{N}_{\mathrm{p}}\right)$ after two return cycles. This limiting value could correspond to a "saturation" of PTFE particles within the confined zone coupled with the assumptions of the model (rigid particles, no compressibility). However, these first results can also be related to physical reality, suggesting that for the highest surface adhesion values $\left(\mathrm{R}_{(\mathrm{O} / \mathrm{P}) /(\mathrm{P} / \mathrm{P})}\right)$, the "surface" effects prevail over the "volume" effects. In Fig. 11(b), the friction factor $(\mu)$ is plotted versus time for the $\mathrm{C} 1$ combination and for the two values of $\left(\mathrm{R}_{(\mathrm{O} / \mathrm{P}) /(\mathrm{P} / \mathrm{P})}\right)$ considered. The average value of $\mu$ seems to increase with $\left(\mathrm{R}_{(\mathrm{O} / \mathrm{P}) /(\mathrm{P} / \mathrm{P})}\right)$ (so does the friction standard deviation $\Delta \mu$, which requires caution when interpreting the results). In Fig. 12(a1), the tangential velocity distribution Vx is plotted in the model at the end of one return cycle for the combination C1-6. It shows that the main velocity accommodation (where the velocity gradients are highest) is located within a thin layer on the top of the driving boundary surface and within the entire confined zone. The increase of PTFE particle concentration within this zone (cf. Fig. 12(a2)) may lead to the friction factor $\mu$ being controlled by the cohesive forces of both interactions (PTFE/PTFE) and (PTFE/surface).

Table 1

Two "volume" combinations C1 and C2 considered with their significant physico-chemical parameters and several "surface" parameters.

\begin{tabular}{|c|c|c|c|c|c|c|c|c|c|}
\hline \multirow[t]{2}{*}{ Parameter combinations $(\gamma, \mathrm{dw})$} & \multicolumn{6}{|l|}{$\mathrm{C} 1$} & \multicolumn{3}{|l|}{$\mathrm{C} 2$} \\
\hline & \multicolumn{6}{|c|}{ (No PTFE agglomerate formation) } & \multicolumn{3}{|c|}{ (PTFE agglomerate formation) } \\
\hline $\mathrm{R}_{(\mathrm{o} / \mathrm{P}) /(\mathrm{P} / \mathrm{P})}$ & 0.4 & & & & & & 0.04 & & \\
\hline \multirow[t]{2}{*}{$\mathrm{R}_{(\mathrm{P} / \mathrm{b}) /(\mathrm{o} / \mathrm{o})}$} & $\mathrm{C} 1-1$ & $\mathrm{C} 1-2$ & $\mathrm{C} 1-3$ & $\mathrm{C} 1-4$ & $\mathrm{C} 1-5$ & $\mathrm{C} 1-6$ & $\mathrm{C} 2-1$ & $\mathrm{C} 2-3$ & $\mathrm{C} 2-6$ \\
\hline & $7.10^{\mathrm{E} 2}$ & $2.10^{\mathrm{E} 3}$ & $4.10^{\mathrm{E} 3}$ & $1,2.10^{\mathrm{E} 4}$ & $3.10^{\mathrm{E} 4}$ & $4.10^{\mathrm{E} 4}$ & $7.10^{\mathrm{E} 2}$ & $4.10^{\mathrm{E} 3}$ & $4.10^{\mathrm{E} 4}$ \\
\hline
\end{tabular}




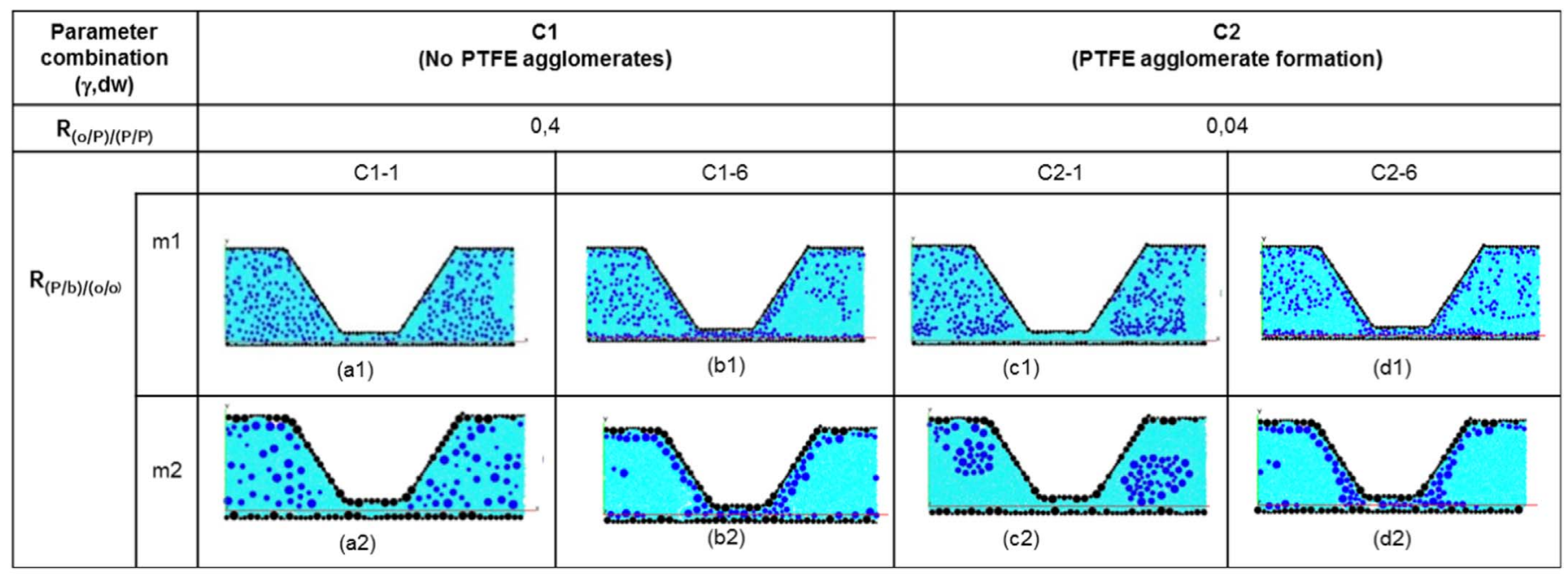

(a)

(b)

(c)

(d)

Fig. 10. Images extracted from the videos after each cycle for all the simulations considered for the following combinations (a) C1-1, (b) C1-6, (c) C2-1, (d) C2-6.

Fig. 12(b) confirms the relation between $\mu$ and the $\left(\mathrm{N}_{\mathrm{p}}\right)$ for the sets of parameters considered.

\subsubsection{Comparison with previous work}

In previous work on space greases [9], it was shown that under some conditions, the largest thickener particles can accumulate at the contact entry and can even prevent smaller particles and oil from lubricating. This is schematized in Fig. 13(a), where the in-situ phenomena were filmed by a video camera through a transparent tool.
Even though real contacts are expected to be more confined and larger than model ones, the m2 GLCM model was used with the "volume" combination $\mathrm{C} 2\left(\left(\mathrm{R}_{(\mathrm{o} / \mathrm{P}) /(\mathrm{P} / \mathrm{P})}\right)=0.04\right)$ associated with strong "surface" adhesion $\left(\mathrm{R}_{(\mathrm{P} / \mathrm{b}) /(\mathrm{o} / \mathrm{o})}=6\right)$ to make a qualitative comparison. The results show a significant accumulation of PTFE particles at the contact entry after one return cycle. These first results suggest that, although not quantitative, the GLMC and GDEM models developed are able to reproduce real tribological phenomena and are relevant as a qualitative tool for understanding the tribological behavior of grease.

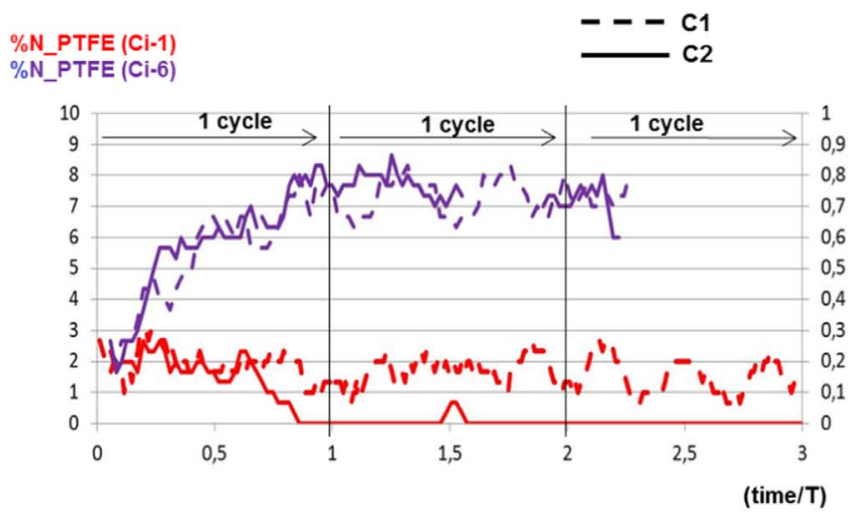

(a)

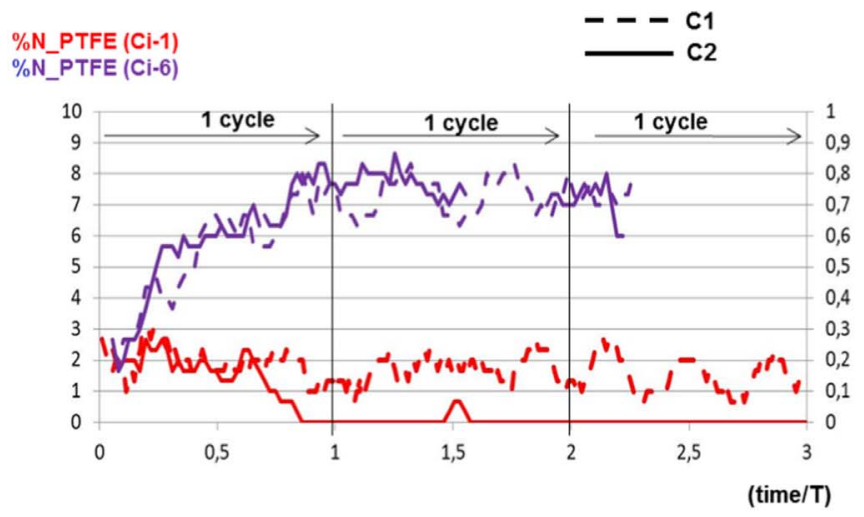

(a)

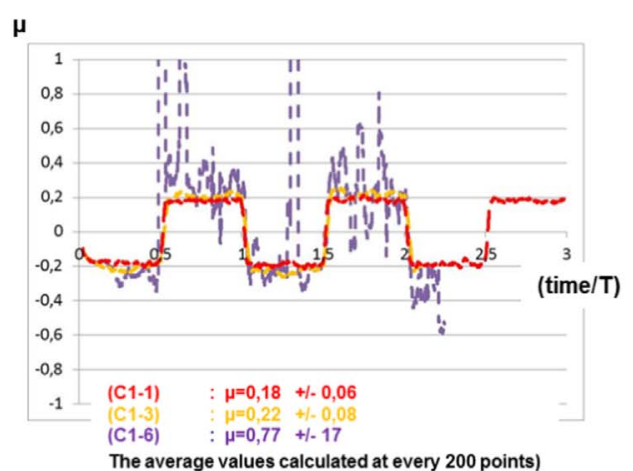

(b)

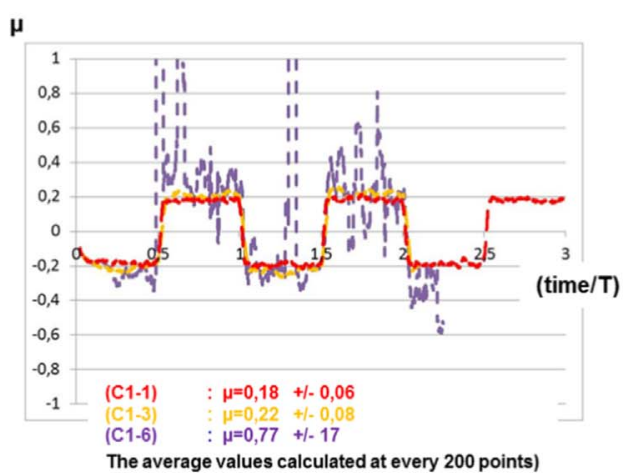

(b)

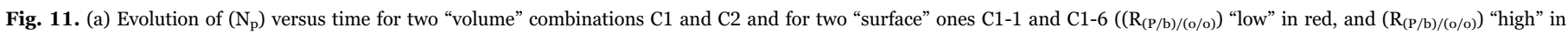

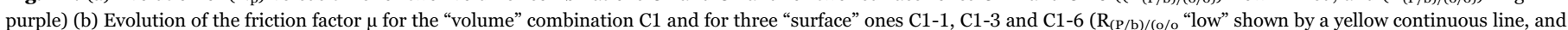

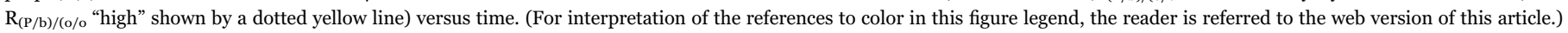




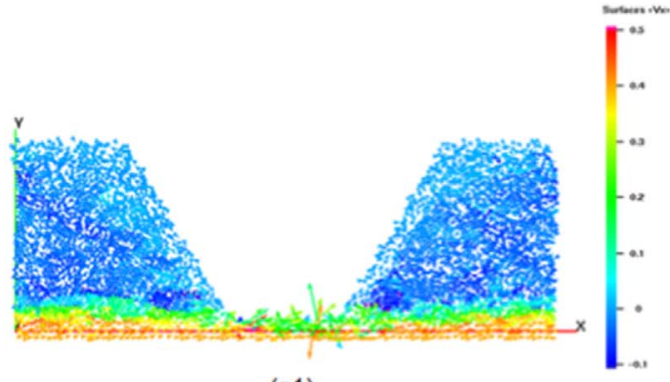

(a1)

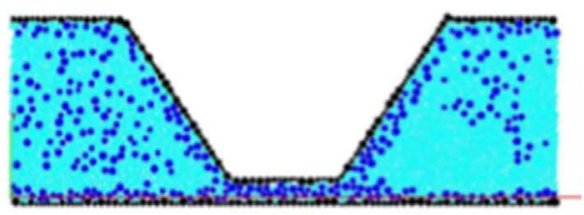

(a2)

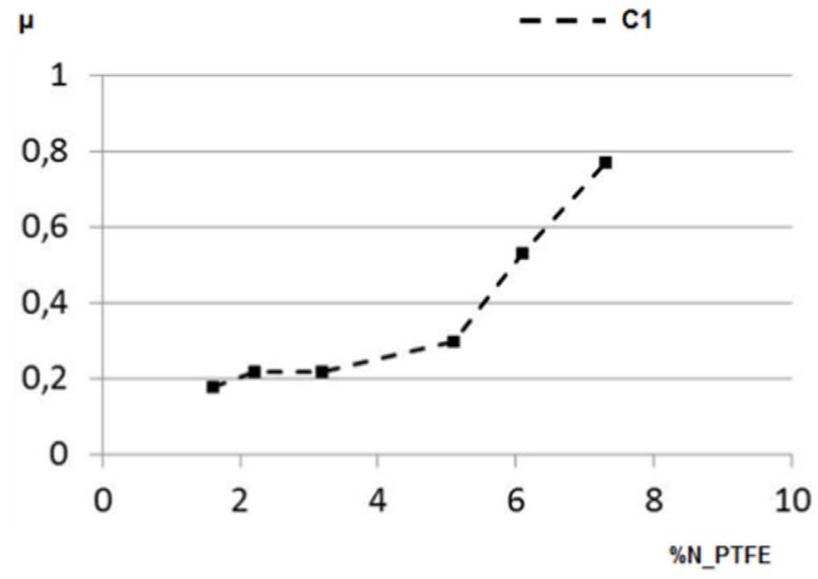

(b)

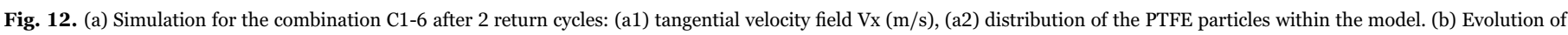
the friction factor $\mu$ versus $\left(\mathrm{N}_{\mathrm{p}}\right)_{\text {final }}$ for the $\mathrm{C} 1$ combination.

(a)

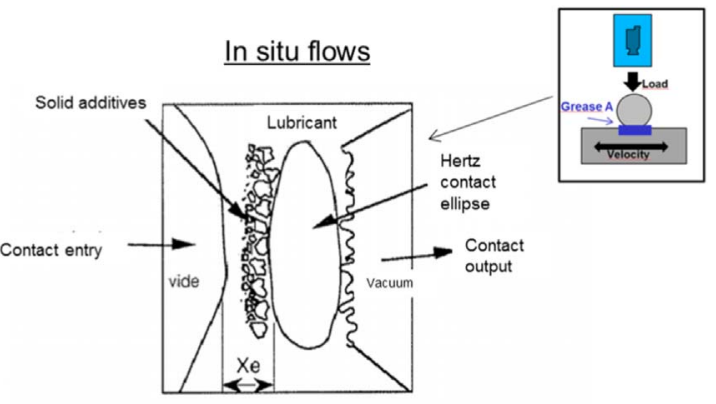

(b)

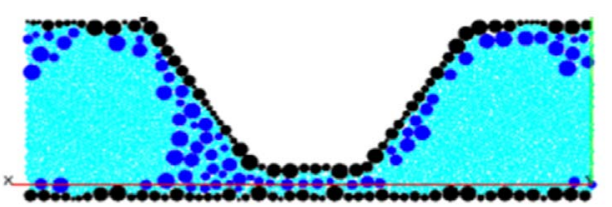

Fig. 13. Comparison between experimental work and modeling. (a) Previous experimental work [10] (The general conditions were illustrated in Fig. 8(a2). In the present experiment developed for contact visualization, the plane test piece was made of glass for permit visualization under pure sliding conditions at $200 \mathrm{~mm} / \mathrm{s}$. The grease used was Braycote 608. (b) Simulation using model $\mathrm{m} 2$ and combination $\mathrm{C} 2$, and high adhesion (C2-3).

\section{Conclusions and perspectives}

In the present work, a Grease Discrete Element Model (GDEM) was developed to investigate the complex discontinuous behavior of grease under tribological conditions. The identification procedure of the interaction parameters, based on rheometer-like simulations, allowed determining the relevant parameters for reproducing the macroscopic behavior of grease in terms of viscosity, although not alone (several parameter combinations are possible for a given macroscopic behavior). Under certain conditions, PTFE particles could agglomerate, modifying the initial grease structure and leading to lower viscosity due to the localization of the velocity accommodation in the oil phase. The viscosity parameter is therefore insufficient for characterizing the "volume" interaction parameters associated with a given grease. As no measure was available for $(\gamma, \mathrm{dw})$, a parametric study was performed on the GDEM subjected to tribological conditions. From the different sets of parameters tested, the tribological behavior of grease seemed to be controlled by the relative influence of both the "surface" and "volume" characteristics of the grease and by the granulometry of the PTFE. When the surface adhesion was relatively "low", the "volume" characteristics of the grease were preponderant. The number of PTFE particles within the confined zone of the contact depended on the presence or not of agglomerated PTFE particles. When the surface adhesion became stronger, a "solid-like" third body layer appeared independently of the "volume" characteristics of the grease. To conclude, the GDEM developed did not describe reality but was shown to be a qualitative tool for understanding the tribological behavior of grease. This modeling work is the first step in identifying the main parameters on which it is necessary to act to reformulate the grease, estimating their order of magnitude and providing the general trends of behavior. In particular, it highlighted the influence of both geometrical (granulometry: PTFE particle sizes) and physico-chemical (interaction parameters) parameters on tribological behaviors. This study showed the importance of obtaining more information on the real structure of grease and elementary PTFE particle distribution, particularly at the contact entry, to determine the significant scale of the behavior involved (interactions between elementary particles and between agglomerated ones). It also showed how it is possible to act on key parameters to obtain an "efficient" grease. In the future, it would be useful to "measure" the physico-chemical parameters of interaction between grease components. The next step of this work will be to consider cohesive "macro-particles" (initial multi-sized particle agglomerates) in models to observe their behavior and their "deformation" when passing through the contact. The investigation of GDEM in a more confined and larger convergent in order to get closer to real contact scales would also be useful.

\section{Acknowledgments}

The authors would like to thank Nathalie Bouscharain, Claude Godeau, Sylvie Descartes and Edouard Régis for their helpful comments.

\section{References}

[1] Zaretsky EV. Liquid lubrication in space. Tribol Int 1990;23(2):75-92.

[2] Furaso RL, Khonsari MM. Liquid lubrication for space applications. NASA Tech Memo 1992:105198.

[3] Kannel JW, Dufrane KF. Rolling element bearings in space. In NASA. Lewis 
Research Center In: Proceedings of the 20th Aerospace Mechanics Symposium (SEE N87-16321 08-39);121-132; 1986.

[4] Briscoe HM. Why space tribology?. Tribol Int 1990;23(2):67-74.

[5] Lugt PM. Modern advancements in lubricating grease technology. Tribol Int 2016;97:467-77.

[6] McMurtrey EL. Lubrication handbook for the space industry. Part A: solid lubricants. Part B: liquid lubricants. NASA/TM 1985:86556.

[7] Sicre J, Vergne P, Reynaud P, Berthier Y, Godet M. Tribological Characterization of spatial wet lubricants under vacuum. In: Proceedings of the fifth European Space Mechanism and Tribology Symposium, ESA SP-334, ESTEC, Noordwijk, The Netherlands, 28-30 October 1992;157:163; 1993.

[8] Sicre J, Berthier Y, Flamand L, Reynaud P, Vergne P, Godet M. Rheological and tribological characterisation of six wet lubricants for space. J Synth Lubr 1994;11(1):35-44.

[9] Reynaud P. Contribution à l'étude de la lubrification liquide sous vide. Application aux mécanismes spatiaux. Thèse de doctorat, INSA de Lyon, mars 1994.

[10] Sicre J, Vergne P, Prat P, Pochard M. New considerations on fluid lubricants for spacecraft applications. European Space Agency, Provided by the NASA Astrophysics Data System; 1995:169:176.

[11] Marchetti M, Jones WR, Sicre J. Relative lifetimes of MAPLUB greases for space applications. NASA/TM 2002:211875.

[12] Buttery M. An evaluation of liquid, solid and grease lubricants for space mechanisms using a spiral orbit tribometer. Proceedings of the 40th Aerospace Mechanisms Symposium, NASA Kennedy Space Center, May 12-14; 2010.

[13] Cann PM. Grease lubrication of rolling element bearings - role of the grease thickener. Lubr Sci 2007;19:183-96.

[14] Cyriac F, Lugt PM, Bosman R, Padberg CJ, Venner CH. Effect of thickener particle geometry and concentration on the grease EHL film thickness at medium speeds. Tribol Lett 2016;61:18.

[15] Bhardwaj V, Pandey RK, Agarwal VK. Experimental investigations for tribodynamic behaviours of conventional and textured races ball bearings using fresh and MoS2 blended greases. Tribology International 2017;In Press, Accepted Manuscript, Available online 26 January; 2017.

[16] Gonçalves D, Graça B, Campos AV, Seabra J. Film thickness and friction behaviour of thermally aged lubricating greases. Tribol Int 2016;100:231-41.

[17] Rezasoltani A, Khonsari MM. An engineering model to estimate consistency reduction of lubricating grease subjected to mechanical degradation under shear. Tribol Int 2016;103:465-74.

[18] Shen T, Wang D, Yun J, Liu Q, Liu X, Peng Z. Tribological properties and tribochemical analysis of nano-cerium oxide and sulfurized isobutene in titanium complex grease. Tribol Int 2016;93:332-46.

[19] Wang L, Wang B, Wang X, Liu W. Tribological investigation of CaF2 nanocrystals as grease additives. Tribology Int 2007;40:1179-85.

[20] Gow G. The time factor in grease rheology. NLGI Spokesm 1988:415-23.

[21] Bair S. The high-pressure rheology of a soap-thickened grease. Tribol Trans 1994;37(3):646-50.

[22] Williamson BP, Walters K, Bates TW, Coy RC, Milton AL. The viscoelastic properties of multigrade oils and their effect on journal-bearing characteristics. J Non-Newton Fluid Mech 1997;73:115-26.
[23] Coussot P, Leonov AI, Piau JM. Rheology of concentrated dispersed systems in a low molecular weight matrix. J Non-Newton Fluid Mech 1993;46:179-217.

[24] Roussel N, Le Roy R, Coussot P. Thixotropy modelling at local and macroscopic scales. J Non-Newton Fluid Mech 2004;117:85-95.

[25] Madiedo JM, Franco JM, Valencia C, Gallegos C. Modelling of the non-linear rheological behavior of a lubricating grease at low-shear rates. Trans ASME J Tribol 2000;122:590-6.

[26] Yoo JG, Kim KW. Numerical analysis of grease thermal elastohydrodynamic lubrication problems using the Herschel-Bulkley model. Tribol Int 1997;30(6):401-8.

[27] Chapkov AD, Bair S, Cann P, Lubrecht AA. Film thickness in point contacts under generalized Newtonian EHL conditions: numerical and experimental analysis. Tribol Int 2007;40:1474-8.

[28] Heirendt L, Liu HHT, Wang P. Aircraft landing gear greased slider bearing steadystate thermos-elastohydrodynamic concept model. Tribol Int 2015;82:453-63.

[29] Wachs A. A DEM-LDM/FD method for direct numerical simulation of particulate flows: sedimentation of polygonal isometric particles in a Newtonian fluid with collisions. Comput Fluids 2009;38:1608-28.

[30] Topin V, Monerie Y, Perales F, Radjai F. Collapse dynamics and runout of dense granular materials in a fluid. Physical Review Letters, 109. American Physical Society; 2012. p. 188001.

[31] Mutabaruka P, Delenne JY, Soga K, Radjai F. Initiation of immersed granular avalanches. Phys Rev F 2014;89:052203.

[32] Elrod HG, Brewe DE. Numerical Experiments with Flows as a Tribological Mechanism - A First Look. Leeds-Lyon Symposium on Tribology, Elseviers; 1991:219-26.

[33] Renouf M, Cao HP, Nhu VH. Multiphysical modelling of third-body rheology. Tribol Int 2011;44:417-25.

[34] Somfai E, Morozov AN, Saarloos WV. Modeling viscoelastic flow with discrete methods. Physica A 2006;362:93-7.

[35] Champagne M, Renouf M, Berthier Y. Modelling Wear for Heterogeneous Bi-Phasic Materials Using Discrete Elements Approach. J Tribol Trans ASME 2014; 136:021603-NaN

[36] Cundall PA, Strack ODL. A discrete numerical model for granular assemblies. Géotechnique 1979;29(1):47-65.

[37] Moreau JJ, Panagiotopoulos PD. Nonsmooth Mechanics and Applications. WienNew York: Springer-Verlag; 1988.

[38] Azema E, Descantes Y, Roquet N, Roux J-N, Chevoir F. Discrete simulation of dense flows of polyhedral grains down a rough inclined plane. Phys Rev 2012;E86:031303.

[39] Renouf M, Bonamy D, Dubois F, Alart P. Numerical simulation of two-dimensional steady granular flows in rotating drum: on surface flow rheology. Phys Fluids 2005; $17: 103303$

[40] Dube MJ, Bollea D, Jones WR, Marchetti M, Jansen MJ. A new synthetic hydrocarbon liquid lubricant for space applications. Tribol Lett 2003;15(1).

[41] Sicre J, Vergne P, Guillaumon O, Jugniot P. Perpetuation of MAPLUB grease range. Proceedings of 13th European Space Mechanisms and Tribology Symposium, ESMATS 2009, Vienna, Austria; 23-25 Sept. 2009. 